\title{
Debt Policy in a Competitive Two-Sector Overlapping Generations Model
}

\author{
Partha Sen \\ Email: partha@econdse.org \\ Delhi School of Economics \\ University of Delhi
}

\section{Working Paper No. 137}

Centre for Development Economics

Department of Economics, Delhi School of Economics 
Working paper No. 137

\title{
Debt Policy in a Competitive Two-Sector Overlapping Generations Model
}

\author{
Partha Sen
}

\begin{abstract}
We analyse debt policy in a two-period, two-sector overlapping generations model with Leontief technologies. We find that debt, issued to transfer resources to the initially old, could be welfare improving in the new steady state for an economy which satisfies the usual conditions for dynamic efficiency viz. the rate of interest is at least as great as the population growth rate. Out of steady state, the only potential losers are the recipients of the transfer. This could happen if the interest rate were to fall sufficiently to offset the effect of the transfer. From generation one onwards everyone becomes better off (under reasonable asumptions). Contrast this with a one-sector model where the definite gainers are those who are alive on date one.
\end{abstract}

Keywords: Government Debt, Overlapping Generations, Two-Sector Models, Dynamic Efficiency.

JEL Classification: E2, E6.

\section{Acknowledgement:}

I wish to thank V.Bhaskar, Saqib Jafarey, Roger Guesnerie, Andrew John and Tim van Zandt for helpful discussion and comments. 


\section{Introduction}

In one-sector two-period competitive overlapping generations models, capital is crowded out if a transfer is made by the government to the old in the initial period and this is financed by issuing debt. ${ }^{1}$ The generation receiving the handout gains as also the next generation. The former gain because both their savings and the return on these is fixed and hence their real income goes up due to the transfer. The generation born in the period that the transfer is made gains because (i) their wages are predetermined, (ii) the interest rate on their savings rises as a consequence of a lower stock of capitalthis is due to the fact that debt crowds out capital—and (iii) they do not need to service the debt. In a closed economy the steady state welfare is lower due to the crowding out of capital. This is because a part of the savings of the young now has to be allocated to the holding of the debt, and, in addition, taxes have to be raised to pay the interest burden that the debt imposes. ${ }^{2}$ All this presumes that the economy is dynamically efficient i.e., in a one sector framework the interest rate ( $r$ ) is not less than the population growth rate $(n)$ (or equivalently profits are at least as much as investmentsee Phelps (1965) and Abel et al. (1989)). In other words, the capital stock is less than the one associated with Phelps' "Golden Rule".

In a competitive two-sector overlapping generations model, I look at the effect of an increase in government debt on welfare, especially in the new steady state. ${ }^{3}$ Technologies in both the sectors are assumed to be Leontief. ${ }^{4}$ With Leontief technologies, the model is stable only if the consumption good is capital-intensive. ${ }^{5}$

1 The overlapping generations models do not exhibit Ricardian Equivalence. See Persson (1985)for a discussion in a two period framework.

${ }^{2}$ See Persson (1985) for a discussion of this both in an open economy and a closed economy framework of Diamond (1965). Shell (1971), Buiter (1981), Matsuyama (1991) and Lang (1996) discuss dynamic efficiency and overaccumulation in overlapping generations models. For a recent monetary model in a two period overlapping generations context see Bhattacharya et al. (2004). For analyses of debt in dynamic macroeconomic models also see Gertler (1999), Grinols and Turnovsky (1998)), Ihori (1978) and Jensen and Nielsen (1995).

${ }^{3}$ See Calvo (1978) who was an early user of a two-sector overlapping generations model with Leontief technologies. Galor (1992), Azariadis (1993) Cremers (2001) and Cremers (2004) also use the two-sector overlapping generations model.

${ }^{4} \mathrm{~A}$ brief discussion of what happens with positive elasticities in production is given in notes available from the author.

${ }^{5}$ There is some empirical support for the assumed capital intensity. See e.g., Takahashi, Mashiya and 
Government debt issued to finance transfers to the old increases the steady state welfare (under very reasonable conditions) in an economy which satisfies the usual conditions for dynamic efficiency viz. $r>n$. This happens not because the stock of capital changes--capital accumulation is left untouched--but because relative prices (including factor earnings) do. The real wage rate rises and the real interest rate falls along the adjustment path and in the steady state. The fall in the rate of interest takes the economy towards the "Golden Rule".

The rest of the paper is organised as follows: in section 2, I set out the model. Debt policy is introduced in section 3, while section 4 concludes. An Appendix derives some tedious expressions used in the text.

\section{The model}

The economy consists of overlapping generations of individuals or households. Each household lives for two periods. It supplies one unit of labor in the first period of its life and in the second period consumes the saving from the first period plus the return on these savings. There are no bequests or inheritances. The population is constant. The analysis is conducted by taking a log-linear approximation (around the initial steady state-one without debt) to the various behavioural and market-clearing equations.

The representative household born in time period t maximizes the following utility function

$$
U_{t}=U\left(C_{t}^{t}, C_{t+1}^{t}\right)
$$

where $C_{t+i}^{t}$ is the consumption in period $t+i$ of a household born in t. The utility function $U($.$) is increasing, strictly concave and satisfies the Inada conditions.$

Its lifetime budget constraint (without taxes, which are introduced later) is

$$
W_{t}=C_{t}^{t}+\left(1+r_{t+1}\right)^{-1} \cdot C_{t+1}{ }^{t}
$$

where $W_{t}$ is the wage rate in time period $t$ and $r_{t+1}$ the own interest rate on one period consumption loans between $t$ and $t+1$. 
This yields

$$
\begin{gathered}
C_{t}^{t}=C^{1}\left(W_{t}, 1+r_{t+1}\right) \\
C_{t+1}^{t}=C^{2}\left(W_{t}, 1+r_{t+1}\right) \\
\left.S_{t} \equiv \arg \max U\left(W_{t}-S_{t}\right),\left(1+r_{t+1}\right) \cdot S_{t}\right)=S\left(W_{t},\left(1+r_{t+1}\right)\right)
\end{gathered}
$$

where $S_{t}$ is the saving in period t. I assume that both period consumption are normal and the interest-elasticity of savings is positive i.e., $0<S_{W}<1, S_{r}>0$. I shall further assume: (i) that the interest elasticity of savings is "small"-see the analysis of stability below; and (ii) without loss of generality, the wage-elasticity of savings is unity-this is to avoid notational clutter.

The indirect utility function is given by

$$
V_{t}=V\left(W_{t},\left(1+r_{t+1}\right)\right)
$$

The production side of the economy is represented by the two cost-equal-to-price equations. ${ }^{6}$ The consumption good (C) and the investment good (I) are produced under conditions of constant returns to scale with Leontief technologies using the two inputs, capital (K) and labor (L). All inputs are mobile between sectors instantaneously. Capital is assumed to depreciate completely in the process of production -- not a bad assumption for a model where a single period corresponds to about 35 to 40 years! $^{7}$

$$
\begin{aligned}
& a_{L C} \cdot W_{t}+a_{K C} \cdot R_{t}=1 \\
& a_{L I} \cdot W_{t}+a_{K I} \cdot R_{t}=p_{t}
\end{aligned}
$$

\footnotetext{
${ }^{6}$ See e.g., Matsuyama (1988) for a similar set-up, though in an open economy context.

${ }^{7}$ This is for analytical convenience only and is made elsewhere in the literature e.g., Cremers (2001). Dropping this would require capital gains on the sale of capital to be part of the return to holding of capital. That would still leave the steady state, where there are no capital gains, unaffected
} 
where $a_{i j}$ is the (fixed) requirement of the $i^{\text {th }}$ input $(i=\mathrm{K}, \mathrm{L})$ in the production of the $j^{\text {th }}$ good $(j=C, I), p$ is the relative price of the investment good in terms of the numeraire consumption good, and R is the gross return on capital. Since we assume capital depreciates completely in the process of production, we have in equilibrium: $\left(1+r_{t+1}\right)=R_{t+1} / p_{t} \equiv \rho_{t+1}$.

There are two goods markets and two factor markets. By Walras' Law, if three of these are in equilibrium in any period, then so is the fourth one. We thus have

$$
\begin{gathered}
a_{L C} \cdot C_{t}+a_{L I} \cdot I_{t}=1 \\
a_{K C} \cdot C_{t}+a_{K I} \cdot I_{t}=k_{t} \\
p_{t} \cdot I_{t}=S_{t}=S\left(W_{t}, \rho_{t+1}\right)
\end{gathered}
$$

Equations (6a), (6b) and (6c) are the market clearing conditions for the labor, capital and investment goods markets respectively. The variable $C_{t}$ is the production per worker of the consumption good, $I_{t}$ is the output per worker of the investment good, $S_{t}$ is the saving per head of the young in period $t$ (see equation (2) above) and $k_{t}$ is the capital stock per worker (all in time period t). The constant population size is normalised to two and thus the number of workers is one.

Finally, the investment good becomes capital in the following period and, hence,

$$
k_{t+1}=I_{t}
$$

In the remainder of this section, I log-linearize the model around its initial steady state, where there is no debt, and derive certain expressions that are used repeatedly in the next section.

Log-linearizing (4) and (5) around the initial steady state, where there is no debt, yield 


$$
\begin{aligned}
& \theta_{L C} \cdot \hat{W}_{t}+\theta_{K C} \cdot \hat{R}_{t}=0 \\
& \theta_{L I} \cdot \hat{W}_{t}+\theta_{K I} \cdot \hat{R}_{t}=\hat{p}_{t}
\end{aligned}
$$

where $\theta_{i j}$ is the share of the $i^{\text {th }}$ input in the $j^{\text {th }}$ sector price and a hat over a variable denotes a proportionate change (e.g., $\theta_{L I} \equiv a_{L I}$.W/p and $\hat{x} \equiv d x / x$ ). ${ }^{8}$

From (8a) and (8b) we have (the Stolper-Samuelson effects)

$$
\begin{aligned}
& \eta_{W p} \equiv \hat{W}_{t} / \hat{p}_{t}=-\theta_{K C} / \Delta>0 \\
& \eta_{R p} \equiv \hat{R}_{t} / \hat{p}_{t}=\theta_{L C} / \Delta<0
\end{aligned}
$$

where $\Delta \equiv \theta_{L C}-\theta_{L I}=\theta_{K I}-\theta_{K C}<0$ and $\eta_{x y}$ is the (partial) elasiticity of $\mathrm{x}$ with respect to $y$. The signs in (9a) and (9b) depend on the sign of $\Delta$. We have assumed the consumption good to be capital-intensive, hence $\Delta<0$. The assumed capital-intensity makes $\Omega<0$ (in equations (11a) and (11b)) below.

Equation (9b) implies

$$
\left(\hat{R}_{t}-\hat{p}_{t}\right) / \hat{p}_{t}=\theta_{L I} / \Delta<0
$$

From (6a), (6b) and (6c) we have by log-linearizing

$$
\begin{aligned}
& \lambda_{L C} \cdot \hat{C}_{t}+\lambda_{L I} \cdot \hat{I}_{t}=0 \\
& \lambda_{K C} \cdot \hat{C}_{t}+\lambda_{K I} \cdot \hat{I}_{t}=\hat{k}_{t} \\
& \hat{p}_{t}+\hat{I}_{t}=\hat{W}_{t}+\eta_{S \rho}\left(\hat{R}_{t+1}-\hat{p}_{t}\right)
\end{aligned}
$$

where $\lambda_{i j}$ is the share of the $j^{\text {th }}$ sector in the total employment of the $i^{t^{t h}}$ input (e.g., $\left.\quad \lambda_{K I} \equiv\left(a_{K I} . I\right) / k\right)$. In (10a) and (10b) we have used the assumptions that 
technologies in both sectors are Leontief i.e., the elasticities of substitution between inputs are zero, and in (10c) the wage elasticity of savings is unity. From equations (10a) and (10b), we have the Rybczinski effects

$$
\begin{aligned}
& \eta_{I k} \equiv \hat{I}_{t} / \hat{k}_{t}=\lambda_{L C} / \Omega<0 \\
& \eta_{C k} \equiv \hat{C}_{t} / \hat{k}_{t}=-\lambda_{L I} / \Omega>0
\end{aligned}
$$

where $\Omega \equiv \lambda_{L C}-\lambda_{K C}<0$ (by assumption).

The dynamics of the economy can be represented by two difference equationsequation (7) (using equation (11a)), and equation (10c) (after substituting from equations (8a), (8b), (11a) and (11b) for $\hat{W}_{t}, \hat{R}_{t}, \hat{I}_{t}$ and $\hat{C}_{t}$ in terms of $\hat{p}_{t}$ and $\hat{k}_{t}$, and recognizing $\left.\hat{R}_{t+1}\left(\hat{p}_{t+1}\right)\right)$. These can be linearized around the steady state and written as

$$
\begin{aligned}
& d k_{t+1}=(\partial I / \partial k) \cdot d k_{t} \\
& d p_{t+1}=A d k_{t}+B d p_{t}+\Gamma_{t}
\end{aligned}
$$

where $A \equiv \eta_{I k} p /\left(k \eta_{S \rho} \eta_{R p}\right), B \equiv-\left(\eta_{W p}-1-\eta_{S \rho}\right) /\left(\eta_{S \rho} \eta_{R p}\right)$ and $\Gamma_{t}$ is a time-varying shock (to be discussed below) and where $d x_{t+i} \equiv x_{t+i}-x$ is the deviation of the $\mathrm{t}+\mathrm{i}$ period of any variable $x$ from its steady state value (a variable's steady state value is denoted without a time subscript).

The system comprising equations (12a) and (12b) is recursive because with Leontief technologies I does not depend on p. Turning to equation (12a) first, we see that $\partial \mathrm{l} / \partial \mathrm{k}$ is $\hat{I}_{t} / \hat{k}_{t}$ evaluated at the steady state and thus

$$
d k_{t+1}=\left(\lambda_{L C} / \Omega\right) \cdot d k_{t}
$$

This can only be stable if

\footnotetext{
${ }^{8}$ For an application of the "hat calculus" see e.g., Atkinson and Stiglitz (1980), chapter 6, section 2.
} 


$$
-1<\lambda_{L C} / \Omega<1
$$

which in turn requires $\lambda_{K C}>2 \lambda_{L C}$ i.e., the consumption good is capital intensive. Thus with stability, the convergence is cyclical (because $\lambda_{L C} / \Omega<0$ ).

Debt policy leaves equation (12a) untouched. Hence, starting from a steady state, the behaviour of prices depends on the term B (and, of course, $\Gamma_{t}$ ) in equation (12b). The term B is assumed to be positive and greater than unity ${ }^{9}$, requiring $p$ to be solved forward in time. Note if $-1<B<1$, then we have indeterminacy in that both roots would be stable (see Calvo (1978)).

\section{Increase in government debt}

Suppose starting from a steady state without any debt, in period 1 the government decides to transfer an amount dg to the old (i.e., the generation born on date 0 ) by issuing one-period bonds. The level of debt is held at this level forever. The interest on the outstanding debt is paid by levying a lump-sum tax on the young every period. ${ }^{10} \mathrm{We}$ shall see that the economy reaches a new steady state in period 2. In calculating welfare changes we need to consider (i) the currently old when the policy is introduced (i.e., the generation born on date 0 which receives the transfer), (ii) the generation born in period 1 (they have to hold the debt but there is no debt servicing required yet), and (iii) generation two onwards-these have to hold the debt as part of their portfolios and pay taxes to meet the servicing requirements.

\subsection{Steady State Effects}

If we start off from a steady state then from (7), $k=1$. And thus equations (6a), (6b) and (7) determine $\mathrm{C}, \mathrm{I}$ and k, and these are unaffected by debt policy. In particular,

\footnotetext{
${ }^{9}$ This requires $\theta_{K I}>\theta_{L I} \cdot \eta_{S \rho}$. This equivalent to saying that if $\mathrm{p}$ rises, savings rise--the effect of $\mathrm{W}$ rising outweighs the negative effect of a fall in the real interest rate.

${ }^{10}$ Labour is inelastically supplied so a tax on labour is identical to a lump-sum tax.
} 
$\hat{I}_{1}$ and $\hat{C}_{1}$ are both zero. Remember with Leontief technologies, I and $C$ depend only on $k$ through the full employment conditions (6a) and (6b) and not on factor prices.

Since $I_{1}$ does not change neither do $I_{2}$ and $C_{2}$ (since $I_{1}=k_{2}$ ). Thus $I, k$ and $C$ remain unchanged at the initial steady state values. From period 2 onwards the system reaches its steady state-all the effects in this subsection are time invariant. The steady state effect of an increase in debt is seen in equation (14) (this is equation (6c) with debt)

$$
S(\tilde{W}, \rho)=p . I+d g
$$

where $\tilde{W} \equiv W-r d g, r \equiv(\rho-1)$.

$\tilde{W}$ is wages net of taxes raised to pay interest on the outstanding debt. Note that time subscripts do not appear for $\tilde{W}, \mathrm{R}$ and $\mathrm{p}$, because all values are steady state values.

Log-linearizing (14) we have

$$
\hat{W}-\eta_{S \rho}(\hat{R}-\hat{p})-\hat{p}=\left(S^{-1}+r W^{-1}\right) d g
$$

Or (using equations (9a) and (9c) in (14a))

$$
\hat{p} / d g=\Theta / \Phi>0
$$

where $\Theta \equiv\left[S^{-1}+r W^{-1}\right]$ and $\Phi \equiv\left(-\theta_{K I}+\eta_{S \rho} \theta_{L I}\right) / \Delta>0$ (from the condition $\mathrm{B}>1$, assumed for stability in equation (12b)).

The change in the after-tax wage and the consumption interest rate are given in equations (16a) and (16b) respectively

$$
\begin{aligned}
d \tilde{W} / d g & =\left[-(W / S)\left(\theta_{K C}\right)+r \Delta-r \theta_{L I} \eta_{S \rho}\right] /(\Delta \Phi)>0 \\
d \rho / d g & =\rho\left(\theta_{L I} / \Delta\right) . \Theta / \Phi<0
\end{aligned}
$$


To see what is happening in equation (16a), rewrite equation (14) as

$$
(S(\tilde{W}, \rho)-d g) / p=I
$$

Now, equation (15) tells us that $p$ rises (given $\Phi>0$ ). Wages net of taxes have to rise compared to the initial steady state-a wage multiplier effect--because now savings have to finance not only the given amount of investment but also debt. ${ }^{11}$. Equation (9c) tells us that if $p$ rises, $\rho$ falls.

In the presence of debt-servicing we modify the indirect utility function (equation (3)) for the tax burden required to service the debt (for generation 2 onwards)-see the Appendix for the derivation

$$
V=V(\tilde{W}, \rho)
$$

Hence

$$
\begin{aligned}
& d V / d g=V_{W}\{d \tilde{W} / d g\}+V_{\rho}\{d \rho / d g\} \\
& =V_{W} r\left(-\theta_{L C}+\theta_{K I}-\eta_{S \rho} \theta_{L I}-(r S / W) \theta_{L C}\right) /[\Phi \Delta]
\end{aligned}
$$

A (very weak) sufficient condition for this expression to be positive is that $\theta_{L C}>\theta_{K I}$ (remember that $\mathrm{C}$ is capital-intensive and $\mathrm{I}$ is labor-intensive and $\theta_{L C}$ and $\theta_{K I}$ are shares of factors that $C$ and I respectively not intensive in). We shall assume this to be the case.

The welfare comparison across steady states is shown in Fig.1. On the horizontal axis we have $C_{1}$ and on the vertical axis we have $C_{2}$. The intercept of the budget line on the horizontal axis is the wage net of taxes and the slope is $-\rho(\equiv-R / p)$. Point $\mathrm{E}_{0}$ is the initial equilibrium on indifference curve $\bigcup_{0} \bigcup_{0}$. In the new steady state, the after-tax wage rate rises and the new equilibrium is at $E_{1}$ on $U_{1} U_{1}$. Point $E_{0}$ and $E_{1}$ lie on a

${ }^{11}$ As wages rise, so does the value of investment-pl-in terms of the numeraire,. The StolperSamuelson Theorem assures us that $\mathrm{W}$ rises proportionately more than $\mathrm{p}$. 
straight line $\mathrm{CC}$ with a slope of $(-1)$ given that in the new steady state $\mathrm{dC}=0$ (i.e., the total consumption of the young and the old taken together is unchanged at the level of the initial steady state). The fall in the interest rate takes us towards the "Golden Rule", thereby increasing utility.

\subsection{Period 1}

Equation (6c) (now with debt), in period one becomes

$$
S\left(W_{1}, R / p_{1}\right)=p_{1} I_{1}+d g
$$

Or log-linearizing

$$
\hat{W}_{1}+\eta_{S \rho}\left(\hat{R}-\hat{p}_{1}\right)=\hat{p}_{1}+d g / S
$$

Equation (20) tells us that savings of the young in period 1 have to be allocated between investment and the holding of government debt--the left-hand side of the equation being the savings (this depends on the current wage rate and the next period's return on capital). There is no servicing of the debt yet. Again there is a multiplier effect on wages, but it is smaller than in the steady-state.

Hence (20) becomes (with $\hat{R} / d g$ substituted from equation (17))

$$
d W_{1} / d g=-W\left(\theta_{K C} / \Delta\right)\left[\left(S^{-1}-\eta_{S \rho} \theta_{L C} \Theta\{\Phi \Delta\}^{-1}\right)\right] / \Xi>0
$$

and

$d R_{1} / d g=R\left(\theta_{L C} / \Delta\right)\left[\left(S^{-1}-\eta_{S \rho} \theta_{L C} \Theta\{\Phi \Delta\}^{-1}\right)\right] / \Xi<0$

where $\Xi \equiv\left(-\theta_{K I} / \Delta\right)-\eta_{S \rho}>0$ (because $\Xi \geq \Phi \geq 0$ )

The change in welfare of generation 0 (those receiving $\mathrm{dg}$ ) is ${ }^{12}$

\footnotetext{
${ }^{12}$ This is just the change in their second period consumption.
} 


$$
d V_{0}=d g+k d R_{1}=\left[1+\left\{\left(\theta_{L C}\right) R /(p \Delta \Phi)\left(1-\left\{\left(\eta_{S \rho} \theta_{L C} r W^{-1}\right) /(\Delta \Xi)\right\}\right] d g\right.\right.
$$

This is may be positive or negative. The old receive the transfer but the real rate of interest falls as well. The indirect effect of the transfer (i.e., the fall in the interest rate) could dominate and welfare of the old could fall.

Generation 1 is affected by the transfer solely because they have to generate the savings to absorb the newly issued bonds. Their wages (in period one) rise but the interest rate they face (in period two-i.e., the new steady state) is lower. The change in the welfare of generation 1 is given by

$$
\begin{aligned}
& d V_{1} / d g=V_{W} d W_{1} / d g+V_{\rho} d \rho_{2} / d g \\
& \quad=V_{W}\left[\left(-W \theta_{K C}(\Delta S)^{-1}-1\right)+\left(S \Theta \theta_{L C}\left(\Psi \Delta^{2}\right)^{-1}\left\{\eta_{S \rho} \theta_{K C} W(S)^{-1}-\theta_{K I}\right\}\right] / \Xi\right.
\end{aligned}
$$

The wage rate for generation 1 rises less than that for generation 2 (onwards) but they do not pay any for debt servicing. Hence their take-home pay could be higher. The real interest rate that they face is also higher than that prevailing in the new steady state-- $R_{2} \equiv R$ is the same for both generations one and two onwards, but in period 1 the increase in price is less-hence $\rho_{2}$ is higher. Thus their utility could be higher it would have been without debt-a very weak sufficient condition for this is that $\eta_{s_{\rho}}$ not be "too small". ${ }^{13}$ It is likely to be so for the following numerical values: $S / W=0.5, \theta_{K C}=0.7, \theta_{L I}=0.7, \eta_{S \rho}=0.25$.

\section{Conclusions}

In a two-sector model with zero population growth we looked at the effect of an increase in government debt (due to increased transfers to the currently old) on welfare. We found that debt policy could be welfare-improving (under a very weak sufficient 
condition) in the new steady state for an economy which satisfies the usual conditions for dynamic efficiency viz. $r>n=0$. The young in the first period also gain off (again under very weak conditions). The only potential losers are the initial older generation (generation 0 ), who were the recipients of the transfer. This could happen if the interest rate was to fall sufficiently to offset the effect of the transfer. Debt improves steady state welfare not by changing the stock of capital --capital accumulation is left untouched--but by changing relative prices (including factor earnings). The lowering of the interest rate takes the economy towards the "Golden Rule". In a one-sector model with a smooth technology, the definite gainers are those who are alive on date 1 . There the old in period 1 gain because the transfer increases their incomes, while leaving the interest rate unaffected, and the young because their wage rate is given but the interest rate in their old age rises as a consequence of capital being crowded out.

Finally, I note that while I have obtained the effects of debt policy on welfare with Leontief technologies, qualitatively similar welfare results can be obtained even if the production functions in the two sectors were not Leontief. The requirements are: (a) that the consumption good sector is relatively capital intensive (as is required for stability in this paper), and (b) that elasticities of substitution in both sectors be sufficiently low. In such a set-up the capital stock also moves in response to the issuing of debt but the effect on welfare is qualitatively the same as we have obtained in this paper-these are available in notes from the author.

13 we require as a sufficient condition $\theta_{K C} \eta_{S \rho} W /\left(S \theta_{K I}\right) \geq 1$. 


\section{APPENDIX 1}

In the steady state if we have the utility function $U\left(C_{1}, C_{2}\right)$, then the indirect utility function is $V(W, \rho)$ (which is derived from $U(W-S, S . \rho)$ where $S$ is chosen optimally).

$$
\begin{aligned}
& d V=V_{W} d W+V_{\rho} d \rho \quad \text { Note } V_{W}=\partial U / \partial C_{1}>0, V_{\rho}=S . \partial U / \partial C_{2} \\
& \mathrm{dV}=V_{W}(d W+S . d \rho / \rho) \quad \text { because } U_{1}=\rho U_{2} \\
& =V_{W}(I d p-k d R+S . d \rho / \rho) \quad \text { (from } \mathrm{W}+\mathrm{R} \mathrm{k}=\mathrm{C}+\mathrm{p} . \mathrm{I} \text { and the envelope theorem implies }
\end{aligned}
$$
$d W+k d R=I . d p)$

$$
=V_{W}(d R-R .(d p / p)) / p=V_{W}\left(k d p-\frac{S}{R / p} \frac{R}{p^{2}} d p+\frac{S}{R / p} \frac{d R}{p}-k d R\right)
$$

because the first two terms in the previous line cancel out (i.e., $k=I=S / p$ ), we have $\mathrm{dV}=V_{W} \cdot S \cdot(1-(R / p)) \hat{R} \quad$--this appears as equation (17) in the text.

The intermediate steps to get to equation (18) from equation (17) are

$$
\begin{aligned}
& V_{W}\left\{-\operatorname{Sr} \theta_{L C}\left(S^{-1}+r W^{-1}\right)-r \Phi \Delta\right\} /(\Delta \Phi) \\
& =V_{W}\left\{-\operatorname{Sr} \theta_{L C}\left(S^{-1}+r W^{-1}\right)+r \theta_{K I}-r \eta_{s \rho} \theta_{L I}\right\} /(\Delta \Phi) \\
& =V_{W} r\left(-\theta_{L C}+\theta_{K I}-\eta_{S \rho} \theta_{L I}-(r S / W) \theta_{L C}\right) /[\Delta \Phi]
\end{aligned}
$$




\section{REFERENCES}

Abel, A., Mankiw, N.G., Summers, L.H. and Zeckhauser, R. (1989). 'Assessing dynamic efficiency', Review of Economic Studies, 56, 1 - 19.

Atkinson, A.B., and J.E. Stiglitz (1980). Lectures in Public Economics, McGraw Hill, New York.

Azariadis, C. (1993). Intertemporal Macroeconomics, Basil Blackwell, Oxford.

Bhattacharya, J., J. Haslagand and S. Russell (2004). 'The Role of Money in Two Alternative Models: When is the Friedman Rule Optimal, and Why?' Journal of Monetary Economics (forthcoming).

Buiter, W.H. (1981). 'Time preference and international lending and borrowing in an overlapping generations model', Journal of Political Economy, 89, 769-97.

Calvo, G. (1978). 'On the indeterminacy of interest rates and wages with perfect foresight', Journal of Economic Theory, 19, 321-37.

Cremers, E. (2001). 'General equilibrium with trade balance and real interest parity', EconomicTheory 1 17, 641-63.

Cremers, E. (2004). Dynamic efficiency in the two-sector OLG model", National University of Singapore, Mimeo.

Diamond, P. A. (1965). 'National debt in a neoclassical growth model', American Economic Review', 55, 1126-50.

Galor, O. (1992). 'A two-sector overlapping generations model: A characterization of the dynamical system', Econometrica _26, 1351-86.

Gertler, M. (1999). 'Government debt and social security in a life-cycle model', Carnegie-Rochester Conference on Public Policy, 50, 61-110

Grinols, E.L. and Turnovsky, S.J. (1998). 'Consequences of debt policy in a stochastically growing monetary economy'. International Economic Review, 39, 495-521.

Ihori, T. (1978). 'The Golden Rule and the role of a government in a life cycle growth model', American Economic Review ${ }_{2} 68,389-96$.

Jensen E. S.-H.and Nielsen,S.B. (1995). 'Population ageing, public debt and sustainable fiscal policies', Fiscal Studies, 16, 1-20. 
Lang, G. (1996). On Overlapping Generations Models with Productive Capital, SpringerVerlag, Berlin.

Matsuyama, K. (1988). 'Terms of trade, factor intensities and the current account in a life cycle model', Review of Economics Studies, 55, 247-62

Matsuyama, K. (1991). 'Immiserizing growth in Diamond's overlapping generations model: A geometrical exposition', International Economic Review, 32, 251-62.

Persson, T. (1985). 'Deficits and intergenerational welfare in an open economy', Journal of International Economics, 19, 67-84.

Phelps, E.S. (1961). 'The golden rule of accumulation: A fable for growthmen', American Economic Review, 51, 638-43.

Shell, K. (1971). 'Notes on the economics of infinity', Journal of Political Economy, 79, 1002-11.

Takahashi, H., K. Mashiya, and T. Sakagami (2004). 'The capital-intensity reversal in the post-war Japanese economy-why did Japan grow so fast during 19551975?' Meiji Gakuin University, Mimeo. 


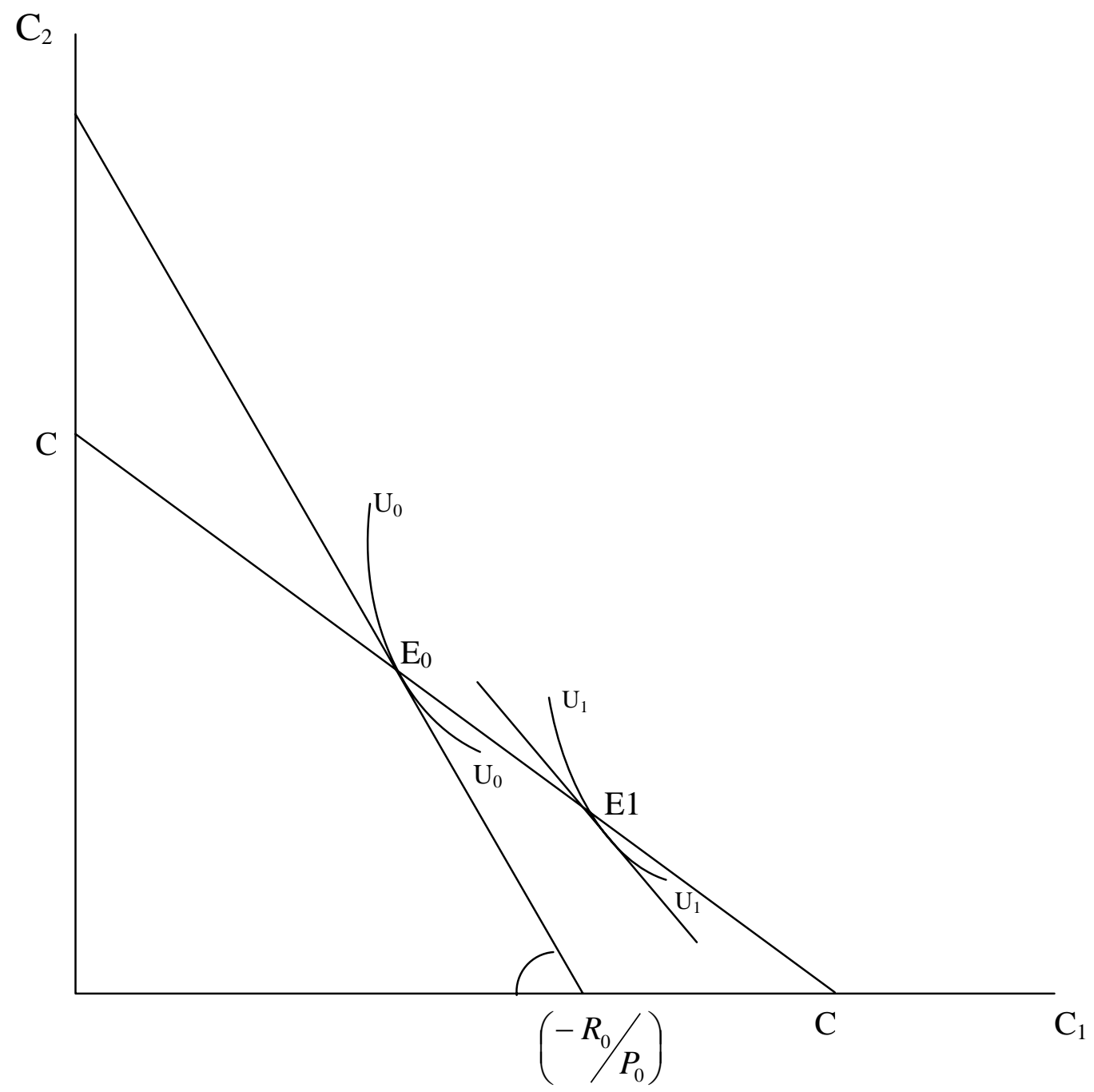

Figure 1

${ }^{*}$ Complete list of working Papers is available at the CDE website:

http://www.cdedse.org/worklist.pdf 